\title{
Fault Detection of Piston Conditions in WATER HYDRAULIC MOTOR BY VIBRATION SigNAL WITH WAVELET ANALYSIS
}

\author{
CHEN, H.X.; CHUA, P.S.K. \& LIM, G.H.
}

Abstract: There has been an increasing application of water hydraulics in industries due to growing concern on the environmental, health and safety issues. The fault diagnosis of water hydraulic motor is important for improving water hydraulic system reliability and performance. Fault diagnosis of water hydraulic motor in water hydraulic system was investigated based on adaptive wavelet analysis. A novel method for modelling the vibration signal based on the adaptive wavelet transform (AWT) was proposed. The model-based method by AWT was applied to extract the features in the fault diagnosis of the water hydraulic motor. This technique for de-noising the corrupted simulation signal showed that it can improve the signal-to-noise ratio of the vibration signal. The results of the experimental signal showed its applicability. The adaptive wavelet analysis was tested by the simulated signals. The results showed that adaptive wavelet analysis can remove the noise from the corrupted signal. The magnitude plots of the adaptive joint time-frequency showed the characteristic signal's energy in time and frequency domain, which can be used as feature values for the fault diagnosis of a water hydraulic motor.

Key words Fault diagnosis; Water hydraulic motor; Adaptive wavelet transform; Genetic algorithm; Parameter optimization; Continuous wavelet transform
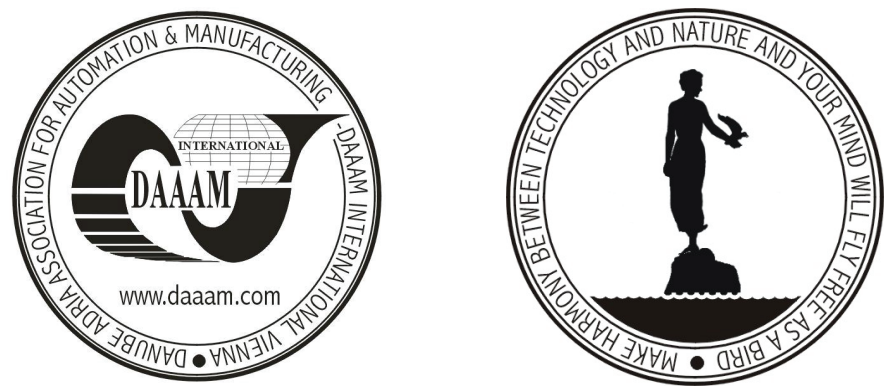

Authors' data: *Dr. Chan H[anxin] X., **Associate Prof. Dr. Chua P[atrick] S.K., **Associate Prof. Dr. Lim G[eok] H., *University of Alberta, Edmonton, Canada, **Nanyang Technological University, Singapore, Pg01074075@ntu.edu.sg, MSKCHUA@ntu.edu.sg,MGHLIM@ntu.edu.sg

This Publication has to be referred as: Chen, H.X.; Chua, P.S.K. \& Lim, G.H (2006). Fault Detection of Piston Conditions in Water Hydraulic Motor by Vibration Signal with Wavelet Analysis, Chapter 12 in DAAAM International Scientific Book 2006, B. Katalinic (Ed.), Published by DAAAM International, ISBN 3-901509-47-X, ISSN 1726-9687, Vienna, Austria.

DOI: $10.2507 /$ daaam.scibook.2006.12 